\title{
¿Es deseable hablar como un nativo?' \\ Reflexiones sobre el acento de los estudiantes de lengua extranjera*
}

\author{
Christine Deprez ${ }^{2}$
}

\section{Resumen}

Para el profesor de lengua y para el especialista en didáctica una buena pronunciación es un criterio importante en la evaluación de las competencias del estudiante. A menudo se afirma que la pronunciación debe ser, si no auténtica, como mínimo casi auténtica; si no nativa, al menos "cercana a la pronunciación nativa».

Pero hablar casi como un "nativo", ¿es hablar sin acento? Imposible, dirá el sociolingüista, ipuesto que todos tenemos un acento! ¿0 es hablar con la pronunciación "estándar"? Pero, ¿no es acaso la lengua "estándar" una abstracción, un constructo pedagógico, una neutralización de las diferencias? ¿Qué tiene entonces dicha pronunciación de auténtico?, ¿y quién es el nativo de referencia?, ¿se trata de un hombre?, ¿es una mujer?, ¿qué edad tiene?, ¿cuál es su profesión?

Para el sociolingüista, el acento es tratado habitualmente desde el ángulo de la variación. Es la marca audible de las características socioculturales de los hablantes, siendo la lengua materna una de ellas. Para este todos tenemos un acento, el nuestro. Un habla sin acento es un mito que muchos han señalado, pero que sin embargo perdura, especialmente cuando se aborda el campo de la lengua "estándar".

Vamos a confrontar, presentando un cierto número de estudios recientes, estos dos puntos de vista, adoptando el tono de la controversia ${ }^{3}$ (se hablará de pronunciación). Nos guiaremos por una doble interrogación. La primera es clásica: ¿Cómo definir la pronunciación ideal o el acento de referencia? La segunda lo es un poco menos: ¿En qué medida el acento, o la ausencia de acento es o sigue siendo relevante en nuestra época?

Palabras clave: acento, sociolingüística, didáctica, test de comprensión oral, categorización, FLE.

1 El presente artículo se traduce con autorización expresa de la autora. Recoge los principales puntos de una comunicación presentada en el Congreso Internacional 2008 Année Européenne du dialogue interculturel: communiquer avec les langues-cultures Université Aristote. Thessalonique, Grecia, diciembre de 2008. Traducido del francés por Pilar Mestre de Caro, doctora en Ciencias del Lenguaje, Universidad Paris Descartes. Correo electrónico: christinedeprez@wanadoo.fr.

2 Pilar Mestre de Caro. Doctora en Ciencias del Lenguaje. Colegio Colombiano de Traductores. pilardecaro@gmail.com

3 Se hablará de pronunciación o de acento para los aspectos didácticos y de acento para los aspectos que atañen al componente sociolingüístico 


\section{Primeras aproximaciones didácticas}

Nuestro colega Boubnova (2006) evoca su experiencia de la manera siguiente:

Como profesor de fonética francesa en Moscú, con frecuencia he escuchado a mis colegas franceses que se encuentran de paso felicitar la pronunciación 'francesa' de nuestros estudiantes. Se preguntaban entonces si los estudiantes rusos serían naturalmente 'dotados' para la fonética o si tal vez dispondrían de métodos de enseñanza particularmente eficaces.

Es posible entender el orgullo de este profesor que ha ganado con sus estudiantes el desafío de la pronunciación "francesa" y se ve recompensado con los cumplidos de los “expertos". Al enseñar el francés a estudiantes avanzados y muy avanzados, la competencia que se busca alcanzar es la del locutor nativo (hablante de lengua materna francesa). Explícito o implícito, el objetivo para el estudiante es convertirse en un "verdadero" bilingüe, es decir, ser capaz de expresarse en las dos lenguas como un hablante nativo, para retomar la famosa definición de Bloomfield.

De manera más frecuente se señala que una pronunciación no acertada de los estudiantes afecta la comprensión del auditor, bloquea el circuito de la comunicación, implica que haya solicitudes de repetición o de aclaración, provoca malos entendidos (Deprez, 1986), intercambios lentos, etc. Por su parte, los jóvenes estudiantes que van a Francia quedan siempre desconcertados por la velocidad de elocución y por la pronunciación de los franceses de edad similar que conocen o que desearían conocer.

A esto se agrega que una pronunciación correcta es también importante a nivel escrito, cuando se plantea la cuestión de la relación entre la fonía y la grafía. Además, es probable que se descuiden los ejercicios de pronunciación en clase de lengua porque se relega la parte oral y porque la evaluación de lengua reposa aún más sobre las producciones escri- $\operatorname{tas}^{4}$. La corrección fonética debe tener un lugar importante en la enseñanza de una lengua extranjera, sin embargo, aunque la mayoría de los profesores interrogados reconocen su importancia, también admiten que se ocupan poco de trabajar la fonética en sus clases, aduciendo otras prioridades.

\section{Cuestión de métodos}

Los métodos de corrección fonética o los ejercicios que trabajan la pronunciación en lengua extranjera están orientados por cierta concepción sobre el origen de los "errores" o de las dificultades que se presentan. Por lo general se suele pensar que estas dificultades provienen de la lengua materna o de otra lengua dominante, por ejemplo el francés (LM) sobre el español (L2). Pero las producciones en L3 (italiano, por ejemplo) estarán influenciadas ya no por una sola, sino por dos lenguas en este caso. Por ejemplo, cuando se busca reproducir el acento musical del italiano interviene ${ }^{5}$ el acento del español que es un acento de intensidad.

El análisis comparativo de los sistemas fuente(s) y objetivo permite comprender los errores que se repiten entre los estudiantes de la lengua extranjera, los cuales comparten con otros estudiantes de misma lengua materna y que se pueden prevenir por medio de ejercicios apropiados en el laboratorio o in vivo. Se califican como hábitos articulatorios los esquemas desplegados en la producción de los sonidos de una lengua (LM) y se habla de interferencias cuando estos hábitos se transfieren a la producción de sonidos de otra lengua y afectan por consiguiente la pronunciación de los sonidos extranjeros. Todo ello fue estudiado en los años setenta, periodo en el que se destacaron los análisis contrastivos que respondían a las expectativas de los profesores de lenguas de colegios o liceos. Hoy en día la idea es retomada y reformulada de la siguiente manera: "confrontado

4 No existe prueba oral en LV2 (Lengua extranjera 2) en el examen de bachillerato general en Francia.

5 Otro ejemplo, algunos taiwaneses recurren al inglés para aprender el francés. 
a las nuevas sonoridades de una lengua extranjera, un estudiante adulto desarrolla una estrategia de apropiación auditiva que opera por medio de similitudes e identificaciones predeterminadas por la categorización fonológica propia de su lengua materna (Boubnova, 2006). Al hablar de "apropiación auditiva" se solicitan las aptitudes para la recepción; la parte de producción interviene posteriormente.

- Los diferentes métodos de pronunciación que se presentan, de manera separada o integrados a los manuales, ilustran diferentes corrientes y en ocasiones algunas tendencias:

- La corriente articulatoria, centrada en la producción del estudiante. Está asociada a la fonética contrastiva y a los ejercicios, trabajan las palabras/sonidos aislados y los pares mínimos para el sentido. Se notará que en esta corriente el estudiante se desempeña como agente, a pesar de sus dificultades, pero esto puede también implicarlo como auditor.

- Los métodos verbo-tonales parten de la idea de que no se puede (re)producir un sonido que no se escucha (sordera selectiva) y enfatizan en los ejercicios de audición: se proponen entornos sonoros que favorecen la percepción de sonidos o de grupos de sonidos que son difíciles de escuchar (podemos pensar por ejemplo en las lenguas a tonos).

- La corriente entonativa se desarrolló considerablemente en estos últimos veinte años. Trabaja más sobre la melodía y la acentuación (Rossi, 1999). Se basa en la importancia de los fenómenos suprasegmentales en la producción contextualizada de la significación (Morel y Danon-Boileau, 1998).

- Los métodos más físicos se interesan en las técnicas del cuerpo, de la respiración y de la relajación para mejorar la receptividad hacia las formas sonoras extranjeras y para vencer el nerviosismo.

- Otras corrientes son más lúdicas y emplean canciones o ejercicios de refranes o dichos como apoyo para la gimnasia articulatoria.

- Algunos manuales se dirigen a un público bien preciso: los hispanohablantes o los chinos, por ejemplo.

- La inmersión (baño lingüístico o aprendizaje en entorno informal) combina varios factores: las interacciones que dan acceso a las producciones de los nativos teniendo en cuenta su gran variedad.

- Por último, la fonoestilística integra prácticas lingüísticas suprasegmentales y se define como el estudio de las funciones sociales, expresivas y apelativas de los enunciados.

Es necesario resaltar la gran diversidad de estos enfoques y el regreso de los estudios sobre la prosodia desarrollados por laboratorios universitarios reconocidos (Vaissière y Boula de Mareüil, 2004).

Pero más allá del método o de la combinación de métodos y de ejercicios que se propongan, encontramos el mismo interrogante: ¿cómo determinar un acento estable que pueda ser considerado como el mejor?

\section{La pluralidad y la diversidad de los "acentos auténticos"}

Los análisis variacionistas más precisos se encuentran en el ámbito la fonética y de la fonología. Por lo general, se diferencian tres tipos de variaciones que afectan a los sonidos: la variación en el espacio (regional), la variación en el tiempo (histórica), la variación social (diastrática).

Las variaciones geográficas (regionales) del francés parecen nivelarse privilegiando una variedad 
más homogénea (Armstrong y Boughton, 1998). Las diferencias sociolingüísticas que se manifiestan en el lenguaje son tan vivaces como otrora, sino aún más. Tras un periodo de uniformización y de estandarización desde el siglo XIX hasta mediados del siglo XX en Francia, hoy en día abordamos una era de mayor diversificación como consecuencia de la vida urbana y de las movilidades internacionales.

Los acentos cambian con el tiempo, cada vez más rápido. Testimonio de estos cambios en curso, principalmente en cuanto a la variación social, son los acentos que se pueden encontrar en internet, grabados en 1983 (hace entonces 26 años) en la casette que acompañaba la obra de Carton, Rossi, Autesserre y Léon (1986): Los acentos del francés. Podemos también comparar los estudios de Martinet (1945) sobre la pronunciación del francés, retomados en 1972 por los estudios de H. Walter. Para los corpus de referencias actualizados y construidos científicamente se consultará especialmente la base de datos sobre "El francés oral contemporáneo: usos, variedades, estructuras", propuesta por el equipo de investigación sobre La Fonología del Francés Contemporáneo $(P F C)^{6}$ dirigida por Durand, Laks y Lyche, en donde los rasgos de la variación están bien integrados.

Estudios recientes tratan de manera específica el tema de la pronunciación de los jóvenes que se escucha en las grandes ciudades y sus suburbios y que desconcierta tanto a los jóvenes extranjeros como a los adultos franceses. El habla de estos jóvenes se ha puesto de moda a través de filmes cultos como $\mathrm{La}$ Haine, Lesquive, Taxi ${ }^{7}$. La tesis de Astésano (2001) trata sobre la evolución del sistema acentual francés, interesándose en los acentos iniciales rítmicos y en los acentos enfáticos frecuentes en el habla de los jóvenes. Hay que destacar también la publicación del libro de Z.Fagyal sobre El acento de los suburbios (Harmattan, 2010).

Esta variedad, a la vez social y generacional, es también regional: los grupos musicales de Toulouse y de Marsella reivindican su acento del sur de Francia y sus influencias artísticas mediterráneas. El acento meridional aparece en las series televisivas y los franceses han librado una batalla sin éxito contra el acento del norte, representado en la película Bienvenue chez les Ch'tis. De cierta forma, se puede considerar que el acento de los inmigrantes es también regional, pues marca su origen extranjero, tal como en su momento lo hicieron los acentos regionales trasplantados a París, los cuales marcaban el origen provincial o rural de sus hablantes.

Las emociones, los afectos (fuera del estrés que puede producir hablar ante otras personas en una lengua cuyos conocimientos son imperfectos), marcan los discursos y las tomas de palabra.

Por último, los géneros discursivos, más o menos formales, o más o menos vigilados, más o menos polémicos, tienen también una incidencia que se demuestra en la pronunciación. A pesar de buscar un punto de referencia estabilizado a nivel del habla individual solo se encuentran variaciones y heterogeneidad (Dreyfus y Prieur). Frente a todas estas variaciones, estos cambios, esta inestabilidad, esta caducidad de las formas de las producciones situadas, la lengua "estándar" aparece pedagógicamente como una abstracción necesaria, cuyos fundamentos deben ser actualizados.

\section{¿Cuáles son los franceses que hablan con el "mejor" acento?}

Los estudios sobre la percepción y la identificación de los acentos utilizan esencialmente los test de

6 Con un acceso especializado para profesores de francés. Publicaciones frecuentes desde el año 2002.

7 De manera más reciente las películas francesas: Dans les murs, La journée de la jupe, La grain et le mulet. 
escucha. El principio es el siguiente: un grupo de auditores nativos se reúne para constituir una muestra representativa de hablantes "estándar"; se les presentan grabaciones o fragmentos de grabaciones para que juzguen por ejemplo los "mejores acentos", o los acentos más cercanos a los suyos. El modo de conformación de estos jurados refleja las ideas de los investigadores al respecto. De esta manera, hace 20 años se podían proponer fragmentos de una emisión literaria animada por Bernard Pivot o la entrevista de un camionero de la región de Turena, de unos 30 años de edad. El primer caso representa el habla de la gente culta, mientras que en el segundo caso se trata de una persona de Turena, región conocida por la calidad y la "pureza" de su francés.

En un estudio que retomaremos más adelante Birdsong (2003) constituye una muestra representativa de hablantes nativos: 17 entre los 21 y los 45 años, de los cuales 7 son mujeres, todos con formación universitaria. Todos eran residentes, al momento de realizar el estudio, de la región parisiense y la mayoría había pasado su vida en el norte de Francia. Se tiene aquí un acento más o menos refinado, «neutro» en cierto modo. Pero se debe admitir que al buscar una cierta homogeneidad se llegará a una construcción social (variedad) compartida a menudo bajo la forma de imaginario lingüístico (Detey y Le Gac, 2008).

\section{Los niños tienen mejor acento que los padres: la hipótesis del periodo crítico}

Esta idea se apoya en observaciones comunes: los niños que aprenden una lengua extranjera tienen mejor pronunciación que los adultos en la misma situación (esto se puede notar en todas las familias inmigrantes). Esta observación atañe a dos modos de explicación: la explicación cognitiva y la explicación interaccionista y constructivista.

La hipótesis del "periodo crítico"8 comparte el anterior posicionamiento. Esta relaciona el factor de la edad con el éxito del aprendizaje. Se afirma que hay una edad ideal para aprender las lenguas, después de la cual el aprendizaje no es imposible, pero sin lugar a dudas más difícil y menos exitoso. Es el argumento de la plasticidad cerebral de los niños alrededor de los 5 años. La capacidad para aprender una lengua disminuiría con la edad, pues los circuitos del aprendizaje de las lenguas se volverían menos maleables puesto que a esa edad todos los niños del mundo aprenden a hablar de manera natural con las personas de su entorno, se recomienda también aprender la lengua lo más pronto posible (los “verdaderos" bilingües no serían sino aquellos que hablan las dos lenguas antes de los cinco años) y emplear un método "natural" para los estudiantes de mayor edad. Se recomienda por consiguiente la inmersión, el famoso "baño lingüístico".

Retomamos por nuestra cuenta los estudios presentados por Pallier, especialista del cerebro bilingüe y de las investigaciones sobre la imaginería cerebral (2006). En lo que respecta la adquisición de una segunda lengua, un estudio de 1995 aborda el acento de los inmigrantes italianos en Canadá con una muestra de 240 personas (entre 2 y 23 años) se comprueba claramente, pero sin sorpresa, que la pronunciación correcta se les facilita más a quienes llegaron desde la primera infancia.

El estudio de Bongaert (2003) se apoya en testimonios de hablantes nativos para mostrar que algunos holandeses que aprenden el francés o el inglés en el colegio a los 12 años pueden tener acentos indiferenciables con respecto a los nativos. Birdsong (2003) retoma la encuesta de Bongaert con norteamericanos que hablan francés; allí muestra igualmente que entre 5 y $25 \%$ de los estudiantes en buenas condiciones, alcanzan un nivel de competencia muy alto.

Si se retoma la argumentación "biológica", la influencia de la edad sobre la competencia en L2 se interpreta dentro del marco de lo que se conoce como

8 En inglés: CPH (Critical Periode Hypothesis).6 En inglés: CPH (Critical Periode Hypothesis). 
el periodo crítico. Las experiencias de Bongaert y de Birdsong con los casos exitosos de bilingüismos tardíos nos muestran que el determinismo biológico no es absoluto y que es posible, bajo algunas condiciones muy favorables, hablar sin acento una lengua cuyo aprendizaje se inició a los 12 años. Los autores prefieren entonces hablar de un periodo "privilegiado", "favorable" o "sensible".

¿Qué nos dicen las imágenes del cerebro en actividad durante los test de lengua? Que cuando existen niveles de competencia iguales en las dos lenguas las áreas que presentan signos de actividad durante las pruebas en cada una de las lenguas tienen tendencia a recubrirse, sin importar la edad de adquisición de la L2. Y las imágenes no han terminado de darnos información...

\section{Enfoques sociolingüísticos}

Para los sociolingüistas la edad es una categorización social. Todas las sociedades emplean categorías de edad que incluyen actividades preferenciales, tipos de relaciones, tipos de interacciones en las cuales, unos y otros, debemos comprometernos. Se trata de la edad social en la cual las reglas de usos lingüísticos se evidencian en la "competencia comunicativa”. Se busca entonces saber cómo se construyen y se definen los usos apropiados de tal o cual variedad o rasgo lingüístico en las diferentes edades de la existencia. Esta observación nos permite comprender por qué los hijos de migrantes aprenden más fácilmente, mejor y más rápido que sus padres la lengua de su nuevo entorno.

Las actividades ligadas al aprendizaje estructural y social del habla y de la escritura son intensas en los niños y perduran a lo largo de su escolaridad. No es el caso de los adultos migrantes, que a menudo tienen otras preocupaciones y no pueden consagrar más que algunas horas, de vez en cuando, al aprendi- zaje de la lengua. A su vez, la cantidad de estímulos espontáneos o controlados, las exigencias y la fuerte presión del medio juegan un factor a favor del niño. El entorno está conformado por los amigos, espacio del cual él no desea ser excluido (peer pressure), y por los adultos, jueces y partes del sistema escolar principalmente. Los problemas son de naturaleza existencial y la acomodación toma entonces matices de inquebrantable asimilación.

Acabamos de evocar las interacciones y su efecto pedagógico y estructurador en los aprendizajes. Cabe anotar aquí que no basta con tener una inmersión en una lengua para absorber y reproducir sus matices.

Es una experiencia que viven muchos estudiantes que participan en cursos lingüísticos en el extranjero durante las vacaciones. En un artículo de síntesis, Pavlenko (2000) recuerda que las sociedades que acogen al extranjero no son siempre muy afables $y$ que en ocasiones es difícil responder en clase, integrar grupos de trabajo e incluso grupos de amigos cuando se es refugiado de Bosnia o japonés en Australia. Se pone en evidencia el hecho de que no todos los acentos extranjeros poseen el mismo valor (Bourdieu, 1982).

\section{¿Cómo identificar e identificarse? ¿Cómo se es identificado, catalogado, evaluado?}

Se dice que el acento lo traiciona a uno, lo descubre, dice quién es uno, de dónde viene... En el mejor de los casos su buena reputación lo privilegia, pero también puede estigmatizarlo. Pigmalión dará lecciones de dicción a su protegida para hacerle perder su acento cockney y hacerla entrar en la sociedad distinguida de Londres (Lodge, 1997). Existe un mercado para ello en los países anglosajones, el business of accent reduction": "Loose your accent in 28 days!” (¡Pierda su acento en 28 días!), mensajes

9 La palabra "mercado" se emplea en los dos sentidos: el mercado comercial (business) y el mercado simbólico del cual habla Bourdieu (1982). 
como este pueden ser leídos en internet. Estas publicidades le apuntan al mejoramiento de las relaciones profesionales y a la integración de los inmigrantes, como por ejemplo en el caso del señor Morales, de apellido hispánico y su hijo en Toronto. Por el contrario, en Miami, capital del bilingüismo inglés/español, otros institutos proponen enseñar el español correcto (incluyendo la pronunciación) a los hijos o a los nietos de inmigrantes que han perdido el buen uso al hablar spanglish, kitchenspanish. Efectivamente, se observa que los niños nacidos en Estados Unidos no tienen la pronunciación de sus padres inmigrantes en su lengua. Tal es el caso en Francia y así se identifica a los jóvenes cuando van de vacaciones al país de sus progenitores. En cuanto a los estudiantes de liceo prefieren tal vez tener el acento de los jóvenes de su edad, en lugar de tener el de su profesor o profesora.

Como lo acabamos de ver en estos ejemplos, la percepción del acento es una etapa previa a la categorización que se hace del hablante. La categorización y las evaluaciones que esta implica se hacen sobre la base de indicadores socio-perceptivos y de evaluadores socioculturales.

Hace aproximadamente 200 años, en el "Discurso sobre la universalidad de la Lengua Francesa” de 1784, el conde de rivarol influenció fuertemente las posiciones políticas de los Revolucionarios sobre la lengua francesa. Mediante de este discurso se establecía un vínculo entre la pronunciación de una lengua y el carácter de los pueblos que la hablan:

Pero la prosa [italiana], compuesta por palabras en las que se pronuncian todas las letras, empleando siempre sonidos completos, se despliega con demasiada lentitud; su cadencia es monótona; el oído se cansa de su suavidad, y la lengua de su apatía [...] El pensamiento más vigoroso es disminuido en la prosa italiana, que a menudo es ridícula y casi insoportable en una boca viril ${ }^{10}$.

Esta transposición metonímica de las cualidades de la lengua (como por ejemplo el alemán, percibido como una lengua gutural) a las de sus hablantes es el principal peligro de estos enfoques. Más grave aún es el vínculo entre la manera de hablar y la manera de $\operatorname{ser}^{11}$.

Rivarol nos recuerda el rol del oído. Por su parte, Susan Fries menciona que si, según el proverbio, la belleza está en el ojo de quien la contempla, "el acento está en el oído de quien lo escucha" (Fries y Deprez, 2004). Esto es lo que efectivamente demuestra su estudio y la mayoría de las experiencias semejantes que acabamos de evocar: se propone (¡una vez más!) a un grupo de hablantes nativos escuchar grabaciones de personas extranjeras o nativas. Ellos reconocen a los locutores extranjeros, pero rara vez están de acuerdo con determinar el origen o la lengua materna de la persona grabada. Numerosas experiencias similares son relatadas en el libro de Lippi-Green (1997).

Los acentos de los profesores de lengua (o de otra materia) no escapan a este fenómeno. R. Lippi-Green narra también la siguiente experiencia: se le propone a unos estudiantes de biología que escuchen el comienzo de una clase y se les sugiere a la vez una foto de la docente. Para algunos la foto corresponde a una mujer europea; para otros es una asiática, pero la grabación es la misma en los dos casos. Podemos imaginar el resto... el curso que se le atribuye a la joven mujer asiática es menos claro y comprensible que el de su colega europea, lo cual confirma una larga serie de estudios experimentales desarrollados mediante los test de escucha, por ejemplo el estudio de Bresnahan, Ohashi, Nebashi, Liu, Shearman

\footnotetext{
9 Comentario de los griegos al referirse a los franceses.

10 Es posible encontrar comentarios como: "los acentos regionales pueden ser un deleite para nuestros oídos, aunque una pronunciación descuidada del francés "clásico" puede hacer parecer al hablante mismo como un sujeto descuidado".
} 
(2002) sobre las reacciones de los estudiantes frente a las pronunciaciones de sus amigos y de sus profesores y a su juicio de inteligibilidad.

\section{Observaciones conclusivas}

Para concluir sería conveniente sacar partido de las observaciones precedentes, haciendo algunas acotaciones en torno a la interrogación introductoria de este artículo: ¿Por qué es deseable hablar "como un nativo"? Es normal que en la enseñanza de una lengua extranjera (LE) se valorice una pronunciación auténtica, pero, ¿se debe por ello desvalorizar una pronunciación extranjera cuando esta no conlleva problema para la intercomprensión?

Hoy en día las fronteras lingüísticas se rompen, la sociedad se abre progresivamente al mundo exterior y los movimientos migratorios se intensifican; la gente interactúa, circula. La ciudad sería entonces el lugar del anonimato por excelencia, a la inversa del campo de otrora donde todo el mundo se conocía. La mezcla de la población combinaría grupos e individuos indiferenciados. Mondada (2001) demuestra por lo contrario que la ciudad es un espacio en el que las actividades de categorización son intensas. El Otro, aquel con el que nos cruzamos, que encontramos, de quien nos alejamos, es categorizado y evaluado en un mismo movimiento. Esta operación de todos los instantes nos permite anticipar los comportamientos que se deben adoptar y producir conductas apropiadas en las diferentes circunstancias de encuentro. Las prácticas urbanas están implícitas mediante de las categorizaciones en un contexto de gran heterogeneidad, un ejemplo de esto es la actividad de clasificación del extranjero, que puede ser fina, si se es capaz de reconocer el origen preciso del hablante, o burda, es decir, simplemente "hablante no francés".

Por otra parte, la lengua "estándar", que aparece como una tentativa pedagógica de construir lo estable en un corpus de producciones orales en las que reina la heterogeneidad y la variación está su- jeta a la evolución, esto se nota al comparar los manuales de acuerdo con su fecha de publicación. La lengua recibe la influencia de las comunidades de inmigrantes que la hablan y que le imprimen marcas específicas. De esta manera, la noción de lengua estándar se vuelve a su vez demasiado variable, por lo que tenderá a ser reemplazada por un concepto en el que habría varias lenguas estándar y por consiguiente ninguna. En estas condiciones es posible preguntarse si las nociones de buena pronunciación como evaluador de las competencias globales y del acento como marcador esencial de la identidad del individuo no están ya un poco caducas.

En el curso de las entrevistas desarrolladas con los estudiantes/bilingües adultos, algunos declaran que no tienen deseo de perder su acento. Es una parte del "alma" de la cual no quieren separarse. Muchas extranjeras residentes en Francia, en pareja mixta por ejemplo, no quieren necesariamente ser asimiladas, ni "pasar" por francesas, es decir por algo que no son.

Por último, resaltemos el ideal realista del "competent foreigner: a new model for foreign language didactics" como alternativa al modelo del locutor nativo (André y Castillo, 2005) y los defensores de la eurocomprensión, de la aproximación, etc. Es necesario admitir que "desenvolverse" en una lengua extranjera no está mal. Eliminemos nuestra soberbia del tiempo de las colonias y no le exijamos a los otros lo que nosotros los franceses no nos imponemos a nosotros mismos: hablar a la perfección la lengua del otro...

\section{Referencias}

Astésano C. (2001). Rythmes et accentuation en français. Invariance et variabilité stylistique. Paris: L'Harmattan.

André V. et Castillo D. (2005). The "Competent Foreigner". A new model for foreign language didactics». In Preisler, A., Fabricius, H., Haberland, S., Kjaerbeck and K. Risager (Eds.). The consé- 
quences of Mobility Roskilde: Roskilde University, Department of Language and Culture.

Armstrong N. and Boughton (1998). Identification and evaluation responses to a French accent: some results and issues of methodology, Paroles, 5/6, 27-60.

Birdsong D. (2003). Authenticité de la prononciation en français L2 chez des apprenants tardifs anglophones: analyses segmentales et globales. In Acquisition et Interaction en Langue Etrangère (A.I.L.E) $\mathrm{N}^{\circ} 18, \mathrm{p} 17$.

Bongaerts T. (2003). Effets de lâge sur l'acquisition de la prononciation d'une seconde langue. In Acquisition et Interaction en Langue Etrangère (A.I.L.E). 18 , p. 15.

Boubnova, G. (2006). «Correction phonétique: enseignement du français/du russe à des russophones/francophones». Revue Française de Linguistique Appliquée, vol. XI.2006/1, pp. 7-19.

Bourdieu P. (1982). Ce que parler veut dire. Léconomie des échanges linguistiques, Paris : Fayard.

Carton F., Rossi M., Auteserre D., Leon P. (1986). Les accents des Français, Paris: Hachette.

Deprez C. (1986). Intercompréhension et malentendus: étude d'interactions entre étrangers et autochtones, in Langue Française, 71, Paris, Larousse, pp. 48-69.

Detey S. et Le Gac T. (2008). «Didactique de l'oral et normes de prononciations. Quid du français «standard» dans une approche perceptive?». Actes au Congrès mondial de Linguistique française, $\mathrm{Pa}$ ris. http://www.linguistiquefrançaise.org.

Dreyfus M. et Prieur J-M. (en préparation). Variations et hétérogénéité: quels objets socio-linguistiques aujourd'hui. Actes du colloque de Montpellier (mai 2009).

Durand J., Laks B. et Lyche C. (dir.) Phonologie du Français contemporain. Accès aux Bulletins par http://projet-pfc.org.
Fagyal Z. (2003). «La prosodie du français populaire des jeunes à Paris: traits héréditaires et novateurs», Le français aujourd'hui, 143, pp. 47-55.

Fagyal Z. (2010). Laccent des banlieues. Etudes phonétiques du rythme du français parisien en contact avec les langues d'immigration. Paris: l'Harmattan.

Fries S. (2000). La différence: les accents américains à Paris, DEA, Université René Descartes-Paris V.

Fries S. et Deprez C. (2003). Laccent étranger: identification et traitement social en France et aux Etats-Unis. Cahiers du Français contemporain. 8, Billiez J. et de Robillard D. (éd.) : Français: variations et représentations, pp. 89-105.

Gueunier N. (2001). «Le français de "référence”: approche sociolinguistique», in Francard M. (éd.) Le français de référence: constructions et appropriations d'un concept, Actes du colloque de Louvain-La-Neuve (3-5 novembre 1999), CILL, 27. 1-2, pp. 9-33.

Lippi-Green R., (1997). English with an Accent. Language, ideology, and discrimination in the United States. London/New York: Routledge.

Lodge A. (1997). Was there ever a Parisian Cockney? in Plurilinguisme, 13, Autour de Pygmalion, pp. 9-34.

Martinet A. (1945). La prononciation du français contemporain, Paris: Droz.

Matter J., (2006). La prononciation authentique: un problème négligé, In Revue Française de Linguistique Appliquée, XII-1, pp. 21-32.

Mondada L. (2001). La ville n'est pas peuplée d'être anonymes in Marges Linguistiques, 3. Recuperado de http//www.texto/.

Morel M-A. et Danon-Boileau (1998). Grammaire de l'intonation: l'exemple du français oral. Paris: Ophrys.

Pavlenko A.(2000). Access to linguistic resources: key variable in second language learning», in Estudios de sociolinguistica, 1(2), 85-105.

Piller I., (2002), Passing for a nativespeaker: identity and success in second language learning». In Journal of Sociolinguistics, 6/2, pp. 179-206 
Ricoeur P. (1990). Soi-même comme un autre. Paris: Seuil.

Rivarol A. (1998). Universalité de la langue française, texte original 1784. Edition Arlea Poche.

Rossi M. (1999). L'intonation, le système du français: description et modélisation. Paris: Ophrys.
Vaissière J. et Boula de Mareuil P. (2004). «Identifying a language or an accent: from segments to prosody», Actes du colloque: http://www.limsi. fr/MIDL/actes/ 